\title{
Coronavirus Disease 2019 (COVID-19) Coronary Vascular Thrombosis
}

\section{Correlation with Neutrophil but Not Endothelial Activation}

\author{
Justin E. Johnson, ${ }^{\star}$ Declan McGuone, ${ }^{\dagger}$ Mina L. Xu, ${ }^{\dagger}$ Dan Jane-Wit, ${ }^{*}$ Richard N. Mitchell, $^{\S}$ Peter Libby, ${ }^{\top}$ and Jordan S. Pober*
}

From the Departments of Immunobiology* and Pathology, ${ }^{\dagger}$ Yale University School of Medicine, New Haven, Connecticut; Department of Cardiology, ${ }^{\ddagger}$ West Haven VA Medical Center, West Haven, Connecticut; and the Department of Pathology ${ }^{\S}$ and the Division of Cardiovascular Medicine, ${ }^{\top}$ Brigham and Women's Hospital, Harvard Medical School, Boston, Massachusetts

Accepted for publication

September 2, 2021.

Address correspondence to Dr. Jordan S. Pober, M.D., Ph.D., 10 Amistad St., Rm 401D, New Haven, CT 06519. E-mail: jordan.pober@yale.edu.

\begin{abstract}
Severe coronavirus disease 2019 (COVID-19) increases the risk of myocardial injury that contributes to mortality. This study used multiparameter immunofluorescence to extensively examine heart autopsy tissue of 7 patients who died of COVID-19 compared to 12 control specimens, with or without cardiovascular disease. Consistent with prior reports, no evidence of viral infection or lymphocytic infiltration indicative of myocarditis was found. However, frequent and extensive thrombosis was observed in large and small vessels in the hearts of the COVID-19 cohort, findings that were infrequent in controls. The endothelial lining of thrombosed vessels typically lacked evidence of cytokine-mediated endothelial activation, assessed as nuclear expression of transcription factors p65 (RelA), pSTAT1, or PSTAT3, or evidence of inflammatory activation assessed by expression of intracellular adhesion molecule-1 (ICAM-1), vascular cell adhesion molecule-1 (VCAM-1), tissue factor, or von Willebrand factor (VWF). Intimal EC lining was also generally preserved with little evidence of cell death or desquamation. In contrast, there were frequent markers of neutrophil activation within myocardial thrombi in patients with COVID-19, including neutrophil-platelet aggregates, neutrophil-rich clusters within macrothrombi, and evidence of neutrophil extracellular trap (NET) formation. These findings point to alterations in circulating neutrophils rather than in the endothelium as contributors to the increased thrombotic diathesis in the hearts of COVID-19 patients. (Am J Pathol 2022, 192: 112-120; https://doi.org/10.1016/j.ajpath.2021.09.004)
\end{abstract}

Hospitalized patients with severe acute respiratory syndrome coronavirus 2 (SARS CoV-2) infection have an increased risk of developing myocardial injury, determined by elevated cardiac troponin concentrations in the blood. ${ }^{1-4}$ Patients with prior cardiovascular disease or risk factors such as myocardial infarction (MI) or hypertension are more likely to develop cardiac injury. However, even individuals without a past history of cardiovascular disease can develop myocardial injury, increasing the risk for acute cardiac complications such as heart failure or chronic cardiomyopathy. ${ }^{5-10}$ Initial considerations of mechanisms included direct viral infection of cardiac myocytes, endothelial cells (ECs), or other cells; autoimmune $\mathrm{T}$ cell-mediated injury resulting in myocarditis;
Supported by NIH grant U01-AI132895 (J.E.J. and J.S.P.), American Lung Association grant ETRA 736563 (D.J.-W.), NIH grant 1R01HL134892 (P.L.), American Heart Association grant 18CSA34080399, the RRM Charitable Fund, and the Simard Fund.

Disclosures: P.L. is an unpaid consultant to, or involved in clinical trials for Amgen, AstraZeneca, Baim Institute, Beren Therapeutics, Esperion Therapeutics, Genentech, Kancera, Kowa Pharmaceuticals, Medimmune, Merck, Norvo Nordisk, Novartis, Pfizer, Sanofi-Regeneron; P.L. is a member of scientific advisory board for Amgen, Caristo, Cartesian, Corvidia Therapeutics, CSL Behring, DalCor Pharmaceuticals, Dewpoint, Kowa Pharmaceuticals, Olatec Therapeutics, Medimmune, Novartis, PlaqueTec, and XBiotech, Inc.; P.L.'s laboratory has received research funding in the last 2 years from Novartis; P.L. is on the Board of Directors of XBiotech, Inc.; P.L. has a financial interest in Xbiotech, a company developing therapeutic human antibodies; P.L.'s interests were reviewed and are managed by Brigham and Women's Hospital and Partners HealthCare in accordance with their conflict-of-interest policies. 
autoantibody-mediated injury through complement activation and/or antibody-dependent cellular cytotoxicity. ${ }^{11}$ However, numerous autopsy studies failed to detect viral protein or RNA within the heart despite evidence of abundant virus presence in the lungs of the patients. ${ }^{12}$ Post mortem examination has also rarely revealed multifocal or diffuse myocarditis along with complement and antibody deposition. ${ }^{12-14}$ Rather, thrombosis of micro and macro coronary vessels has most consistently been observed in the hearts of individuals who succumbed to coronavirus disease 2019 (COVID-19). ${ }^{14-16}$ The underlying cause of this thrombotic diathesis in the hearts of patients with severe COVID-19 is not known, but has been attributed to either alterations in blood composition and/or pathological changes of the endothelial lining of the vasculature. ${ }^{17}$ This study examined heart tissues from autopsies of seven patients with COVID-19 performed early in the pandemic before anticoagulation was commonly administered, and compared these specimens to twelve COVID-19-negative controls, with or without heart disease, using multiparameter fluorescence microscopy to analyze the composition of thrombosed vessels. The current data show that although alterations in endothelium occurred, they were uncommon, and did not generally colocalize with sites of thrombosis. However, activated circulating neutrophils were routinely observed in the thrombi of patients with severe SARS-CoV2 disease.

\section{Materials and Methods}

\section{COVID-19 Cohort Characteristics}

The COVID-19 cohort consisted of 7 patients - 4 males and 3 females, who were positive for SARS CoV-2 infection by RT-PCR with ages ranging from 50 to 94 (Table 1). All patients had severe pneumonia. One patient had a sudden cardiac arrest outside of hospital, two patients developed sepsis, and one patient had recurrent acute leukemia with thrombocytopenia. Length of hospitalization ranged from 2 to 13 days (Supplemental Table S1). The COVID-19 negative controls consisted of 12 patients - 8 males and 4 females, including 6 patients with pre-existing cardiac disease. Multiple sections from 2 randomly selected areas of the left ventricle were examined for each patient and control.

\section{Immunofluorescence of FFPE Tissues}

Formalin fixed, paraffin-embedded de-identified sections of heart tissues were obtained from autopsies performed at Brigham and Women's Hospital and at Yale New Haven Hospital under IRB-approved protocols. Slides were deparaffinized by graded washes in xylene and ethanol. Antigen retrieval was then performed in sodium citrate buffer (Vector, H-3300) for 30 minutes. Sections were incubated with blocking solution containing 1\% BSA, 5\% donkey serum in PBS for at least 1 hour at RT. Primary antibodies reactive with the following antigens were added overnight at $4{ }^{\circ} \mathrm{C}$ : Cleaved Caspase 3 (1:300, Cell Signaling Technology (CST) 5A1E), ICAM-1 (1:300, Novus Biologicals (NB) BBA17), myeloperoxidase (1:200, CST E1E7I), CD45 (1:100 Abcam (ab) ab10558), CD42b (1:100, Thermo Fisher (TF) 42C01; 1:150, TF PA5-109282), VECadherin (1:300, SantaCruz (sc) sc-6458), Fibrin (1:200, Dako A0080), IgM AF647 (1:200 SouthernBiotech (SB) 2020-31), CD11b (1:100 TF M1/70), myeloperoxidase AF647 (1:100, ab252131), CitH3 (1:100, ab5103), p65 (1:400, CST D14E12), pSTAT1 (1:100, CST 58D6), pSTAT3 (1:100, CST D3A7), tissue factor (1:200, CST E9M6T; 1:200 NBP2-61641), VWF (1:50, ab201336), VCAM-1 (1:100, NB 6G9), E-selectin (1:100, TF PA596091), SARS CoV-2 spike (1:200, GeneTex GTX632604), SARS CoV-2 nucleocapsid (1:200, CST HL344), and C4d (1:100, Quidel A213). Samples were washed three times in PBS and then incubated with appropriate AlexaFluor conjugated secondary antibodies and Ulex Europaeus Agglutinin I - FITC/Rhodamine (1:200, Vector RL-1061, 1062) in same blocking solution for 1 hour at room temperature. All antibodies were validated using human tonsils or autopsy heart tissues with myocarditis, sepsis, or myocardial infarction. Secondaryonly controls were used to ensure specificity of primary antibody binding.

\section{Cyclic IF of FFPE Tissue}

To colocalize multiple fluorescent signals on the same field, a cyclic IF method was employed that involved repeated staining and imaging of the same tissue section with quenching of the fluorescent signal between cycles and the use of directly conjugated antibody. ${ }^{18}$ Briefly, coverslips were placed on slides using PBS with $10 \%$ glycerol. After imaging, coverslips were removed by placing slides in a container of PBS for 30 minutes. Sections were then bleached in PBS with $3 \% \mathrm{H} 2 \mathrm{O} 2$ and $\mathrm{NaOH}$ to quench fluorescence. Slides were washed 3 times, then conjugated antibodies were added overnight. Images were recorded at each step and then brought into spatial alignment for colocalization of staining using ImageJ software version 1.53c; Fiji version 2.1.0 (Fiji, https://fiji.sc, last accessed August 23, 2021). ${ }^{19}$

\section{Quantification of Immunofluorescent Signals}

Random single and large (100+) tiled images were taken at $20 \times$ or, when possible, the whole tissue imaged at $10 \times$. Fluorescence was normalized to vessel or tissue area. Ulex and DAPI colocalization was used to determine regions of interest (ROIs) of EC nuclei for quantification of pSTAT1, pSTAT3, and p65 fluorescence. ImageJ was used to process and measure fluorescence of tissue. 
Table 1 Patient Demographics and Clinical Information

\begin{tabular}{|c|c|c|c|c|c|}
\hline $\begin{array}{l}\text { COVID-19 } \\
\text { patients }(n=7)^{*}\end{array}$ & Age & Sex & Cardiac history & Medications & Cause of death \\
\hline Patient 1 & 94 & $\mathrm{~F}$ & CAD & Remdesivir & Pneumonia \\
\hline Patient 3 & 77 & M & None & & $\begin{array}{l}\text { Pneumonia and pulmonary thrombosis } \\
\text { in setting of end stage renal disease }\end{array}$ \\
\hline Patient 4 & 57 & M & None & & $\begin{array}{l}\text { Pneumonia leading to cardiac arrest, } \\
\text { followed by shock }\end{array}$ \\
\hline Patient 6 & 68 & $\mathrm{~F}$ & CAD, MI & & $\begin{array}{l}\text { Pneumonia in setting of CV disease and } \\
\text { recent MI }\end{array}$ \\
\hline Patient 7 & 50 & M & None & Bilnatumomab & $\begin{array}{l}\text { Pneumonia w/DAD in setting of } B \text { cell } \\
\text { ALL relapse }\end{array}$ \\
\hline \multicolumn{6}{|l|}{ Controls $(n=12)$} \\
\hline Control 4 & 58 & $\mathrm{~F}$ & None & & $\begin{array}{l}\text { Respiratory failure from pulmonary } \\
\text { adenocarcinoma }\end{array}$ \\
\hline Control 5 & 58 & M & None & & GI hemorrhage and shock from cirrhosis \\
\hline Control 6 & 46 & $\mathrm{~F}$ & $\mathrm{HOCM}$ & & $\begin{array}{l}\text { Metastatic breast cancer in setting of } \\
\text { HOCM-induced heart failure }\end{array}$ \\
\hline Control 7 & 68 & M & None & & $\begin{array}{l}\text { Pulmonary squamous cell carcinoma } \\
\text { leading to hemorrhage and } \\
\text { desanguination }\end{array}$ \\
\hline Control 8 & 65 & M & CAD & & $\begin{array}{l}\text { Interstitial lung disease complicated by } \\
\text { bronchopneumonia }\end{array}$ \\
\hline Control 9 & 71 & $\mathrm{~F}$ & None & & ILD leading to pneumonia \\
\hline
\end{tabular}

*All patients with COVID-19 were positive for severe acute respiratory syndrome coronavirus 2 (SARS-CoV-2) by RT-PCR.

F, female; M, male; ALL, acute lymphoblastic leukemia; ARDS, acute respiratory distress syndrome; $C A D$, coronary artery disease; $C H F$, congestive heart failure; CKD, chronic kidney disease; DAD, diffuse alveolar damage; DVT, deep venous thrombosis; GI, gastrointestinal; HOCM, hypertrophic obstructive cardiomyopathy; ILD, interstitial lung disease; MI, myocardial infarction; NSTEMI, non-ST elevation myocardial infarction.

\section{Statistics}

Data are expressed as means \pm SEM. Statistical analyses were performed using GraphPad Prism software version 8.4.3 (GraphPad Software, San Diego, CA). The $U$-test was used to make statistical comparisons between two groups. A $P$ value of less than or equal to 0.05 was considered statistically significant.

\section{Results}

Thrombosis Is the Most Common Pathologic Finding in Heart Autopsy Specimens of COVID-19 Cohort

Consistent with prior reports, ${ }^{12}$ extensive micro and macrothrombi were observed in 6/7 of the COVID-19 cohort (Figure 1) and SARS-CoV-2 spike or nucleocapsid antigen indicative of active infection, evidence of multifocal lymphocytic infiltrates indicative of myocarditis, or complement deposition on endothelium indicative of antibody-mediated vasculitis were not detected (Supplemental Figure S1). The only patient without evident thrombosis had a diagnosis of acute lymphocytic leukemia with progressive thrombocytopenia. To quantify the extent of thrombosis, slides of FFPE heart samples were studied using antibodies reactive with platelet protein $\mathrm{CD} 42 \mathrm{~b}$ and/or fibrinogen. Based on these stains, patients with COVID-19 had a highly elevated frequency of platelet-rich microthrombi per $20 \times$ field (Figure 1A) and total number of macrothrombi involving both intramyocardial arteries and veins (Figure 1B) in tissues compared to the COVID-19 negative controls. Several multinucleated giant cells that stained with CD42b, consistent with megakaryocytes, were also observed within the cardiac vasculature of three patients; such cells were not seen in any controls (Figure 1C). 


\section{A}
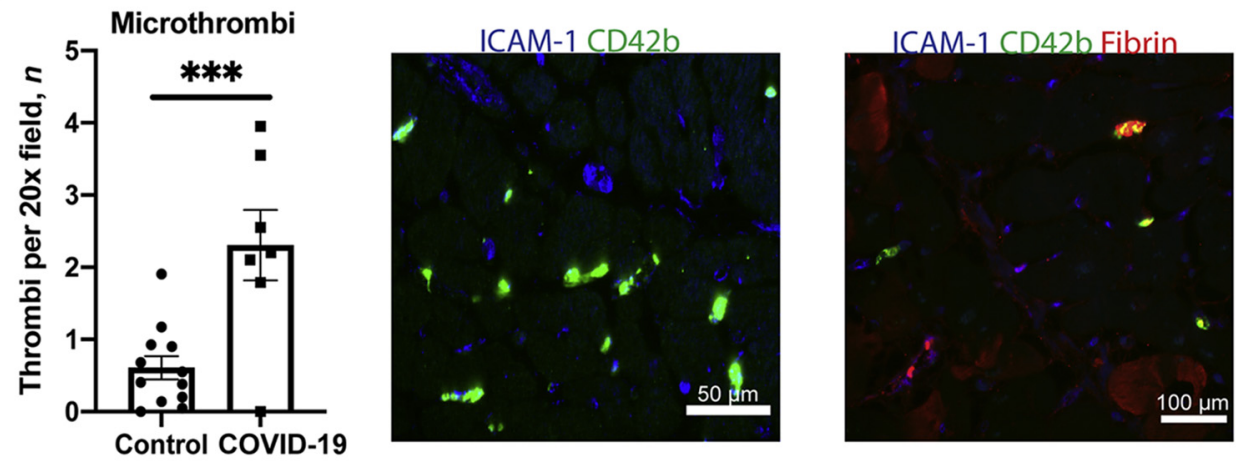

B
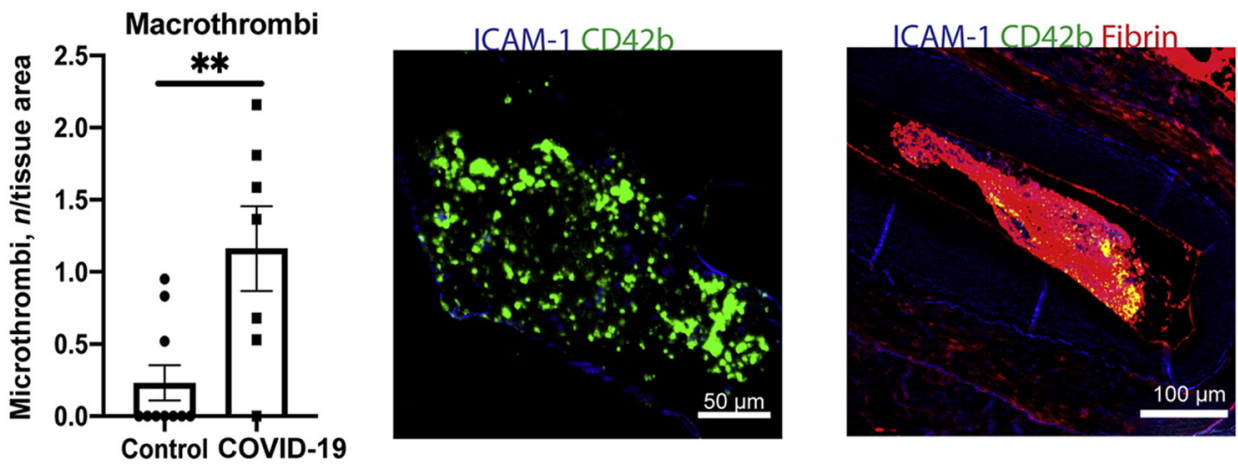

C

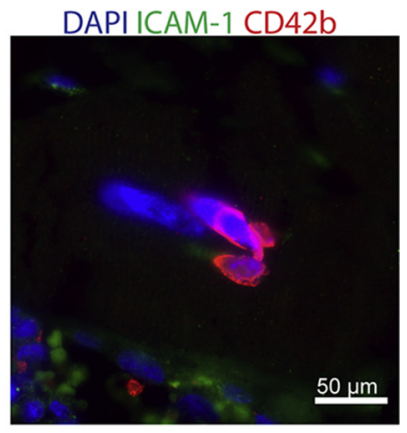

Figure 1 Quantification of micro- and macrothrombosis in hearts of patients with COVID-19. A: The frequency of microthrombi per $20 \times$ field was quantified in controls and patients with COVID-19. Representative images of microthrombi composed of platelets and/or fibrin. B: The total numbers of macrothrombi per tissue section were counted by imaging whole tissue at $10 \times$ and dividing by tissue area. Representative images of macrothrombi composed of platelets and/or fibrin. C: Image of a megakaryocyte present in heart tissue. CD42b was used to identify platelets; ICAM-1 for vessels. Data represent means \pm SEM. ${ }^{* *} P<0.01$, $* * * P<0.001$. Scale bars: $50 \mu \mathrm{m}$ (A and $\mathbf{B}$, left images, and $\mathbf{C}) ; 100 \mu \mathrm{m}$ (A and $\mathbf{B}$, right images).

Despite the widespread evidence of thrombosis, no evidence of myocyte death or acute inflammation typically associated with myocardial infarction was observed.

\section{ECs Show Infrequent Evidence of Injury or Activation in Heart Tissues}

To assess whether endothelial alterations occur in the context of COVID-19-associated cardiac vascular thrombosis, the vessels of the heart were examined for signs of endothelial cell (EC) injury or activation. EC injury by apoptosis can promote thrombosis through release of microparticles containing pro-coagulative tissue factor or by EC sloughing that can expose platelet-activating collagen. ${ }^{20,21}$ Cytokine-activated endothelium may also become procoagulant; e.g., through synthesis of tissue factor, or platelet adhesive by release of high molecular weight von Willebrand factor. ${ }^{22,23}$ Evaluation of intimal injury revealed only rare markers of cleavage/activation of caspase 3 in endothelial cells in 1/7 patients (Figure 2A), unrelated to sites of thrombosis. One patient showed both rare foci of EC denudation with adherent platelets and rare VE-Cadherin+ cell fragments colocalized with platelets (Figure 2, B and C). Another patient had rare foci of tissue factor expression within the vascular lumen but not colocalized with sites of thrombosis (Figure 2D). VWF luminal staining indicated increased percentage of vessels in three patients with COVID-19, but not coincident with sites of thrombosis (Figure 2E). The patient with COVID-19 with the highest level of VWF expression, found in approximately $5 \%$ of vessels, was patient 6 , who had recently suffered a MI. The sample with the second most frequent localization of VWF was from the patient with ALL who showed no signs of thrombosis.

Next, cytokine-activated signaling pathways in the ECs were assessed by both nuclear p65 (Rel A) translocation and STAT protein tyrosine phosphorylation. Nuclear p65, a manifestation of IL-1 or TNF signaling, was limited and of no greater frequency in ECs of patients with COVID-19 versus that in controls (Figure 2F). Endothelial pSTAT1 expression, indicative of IFN signaling, was absent in all but one patient who exhibited expression on $0.6 \%$ of ECs and none at sites of thrombosis (Figure 2G). Similarly, the percentage of ECs with pSTAT3 expression, indicative of responses to IL-6 family of cytokines, did not differ 
A

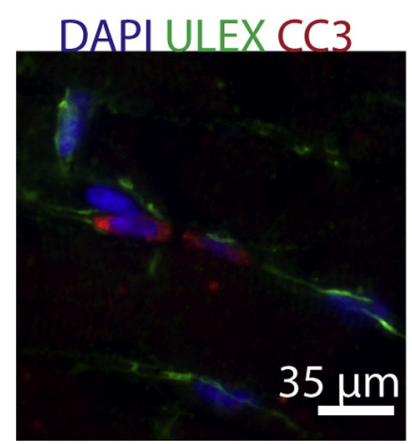

E

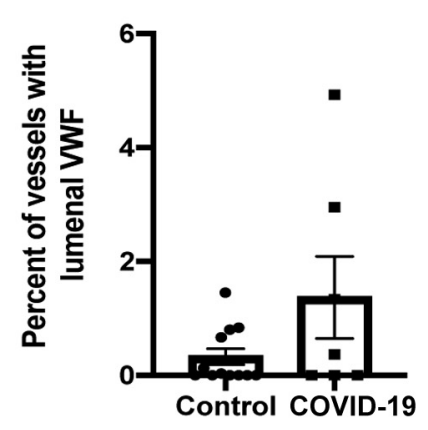

G

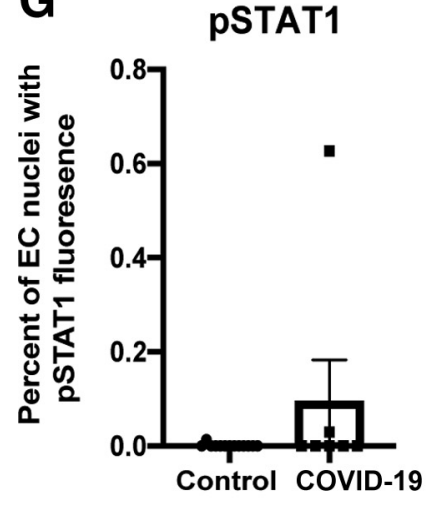

I

ICAM-1

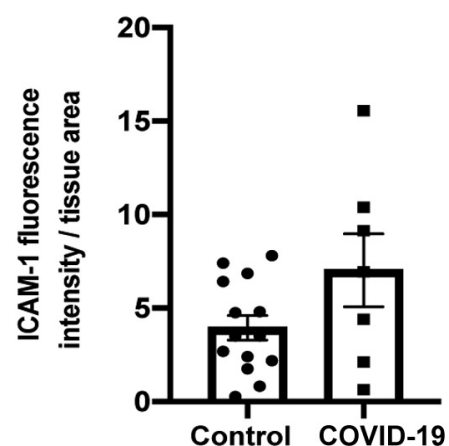

B

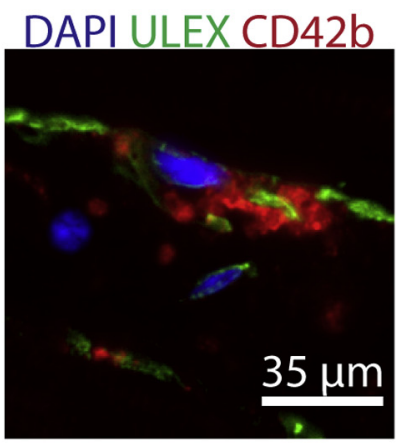

DAPI ULEX VWF

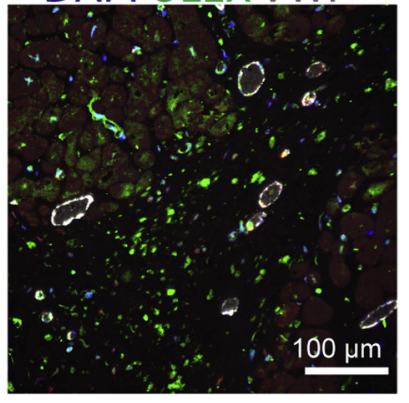

F

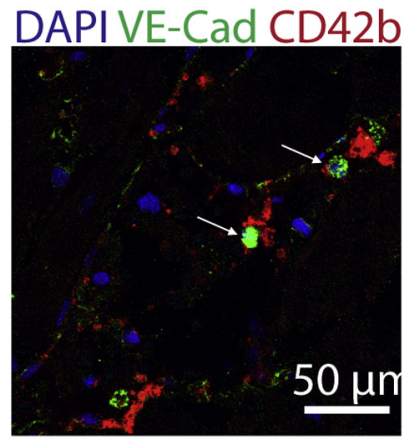

D
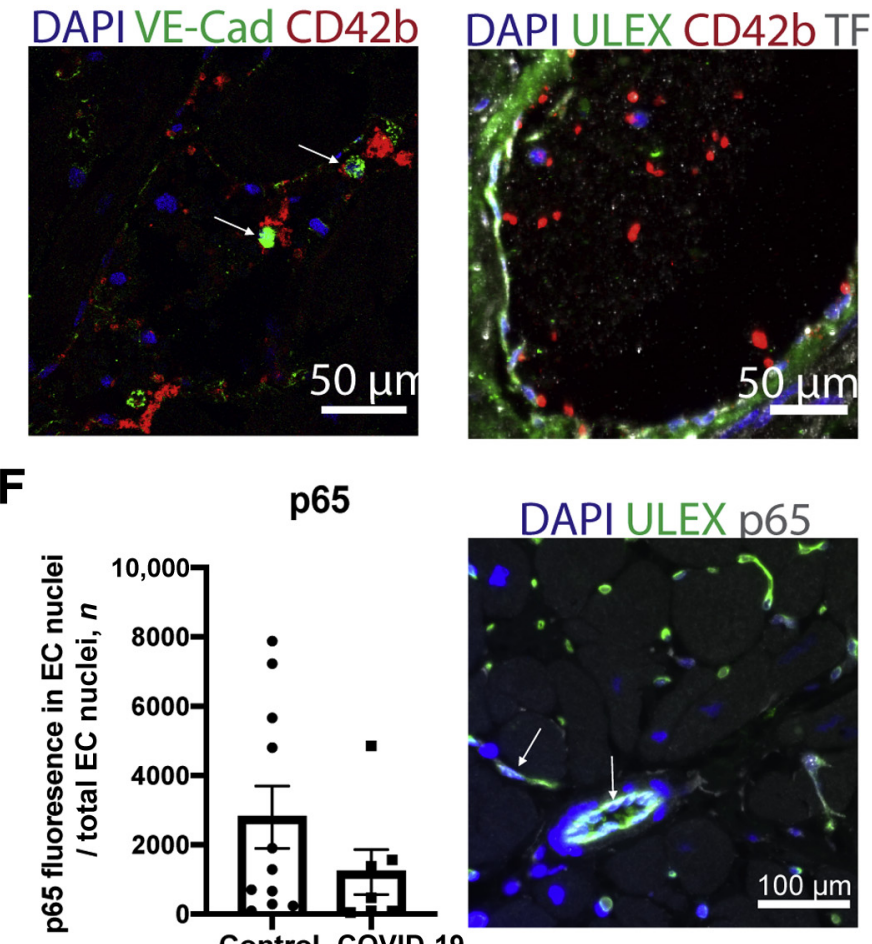

p65

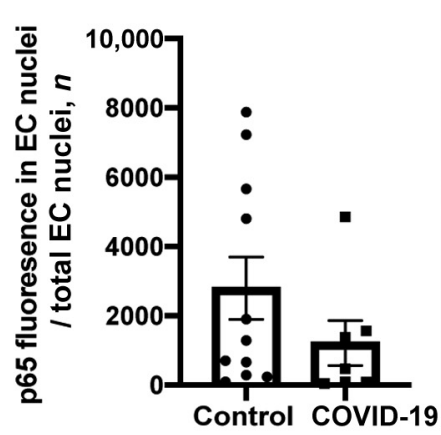

DAPI ULEX p65

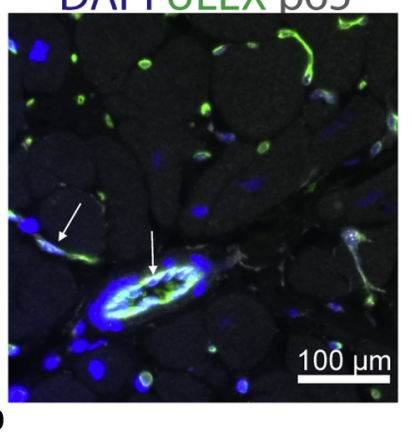

H
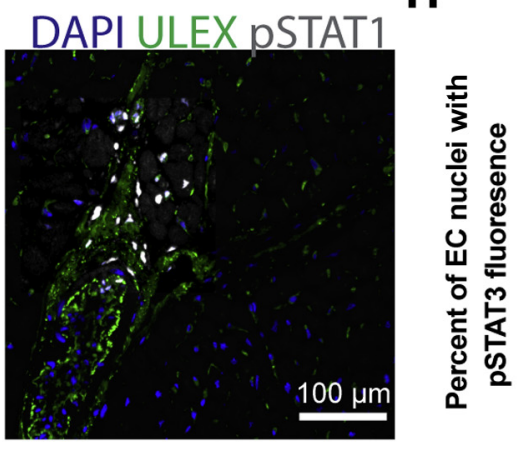

pSTAT3
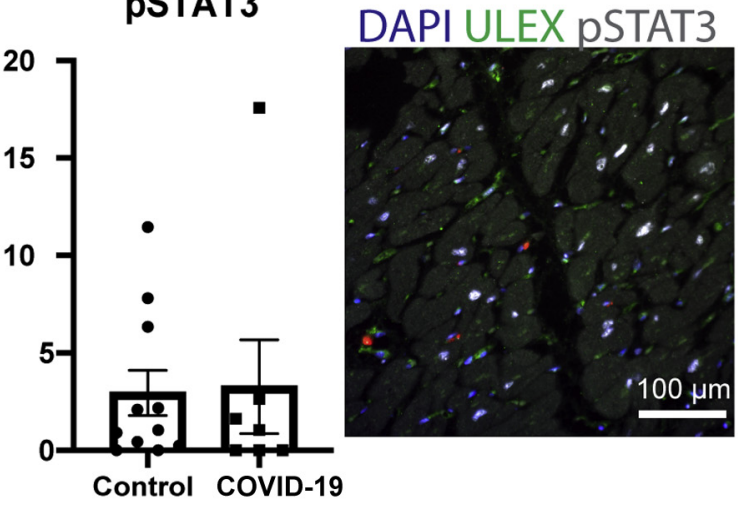

J

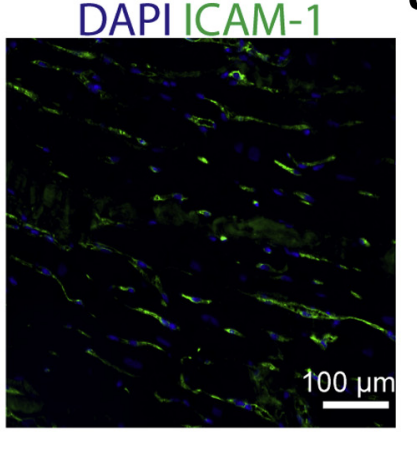

VCAM-1

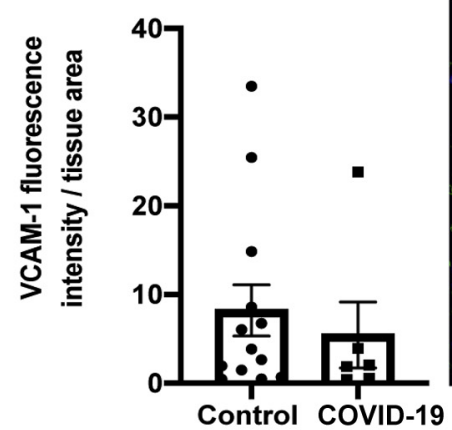

DAPI VCAM-1

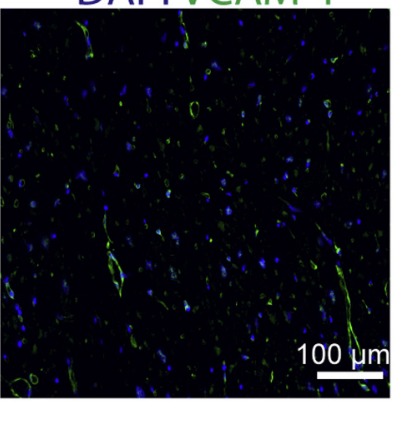

Figure 2 Endothelial cells (ECs) lining heart vasculature show minimal signs of injury or activation. A-C: Images show rare evidence of EC injury in patients with COVID-19 with (A) cleaved caspase 3 (CC3) expression on a few ECS, (B) denuded and sloughed off ECs at a site of platelet aggregation, and (C) circulating VE-Cadherin + cell fragments bound to platelets (arrow). D: Tissue factor on vessel lumen and sites of thrombi was also rarely detected. E-I: Quantification and representative images of EC activation markers. The percentage of vessels with lumenal VWF in control and COVID-19 patients (E). The percentage of EC nuclei that showed (F) p65 nuclear localization (arrow), PSTAT1 (G), or pSTAT3 in patients and controls (H). I and J: ICAM-1 and VCAM-1 fluorescence intensity on vessels was calculated and normalized to area of tissue sampled. Data represent means \pm SEM. Scale bars: $35 \mu \mathrm{m}(\mathbf{A}$ and $\mathbf{B}) ; 50 \mu \mathrm{m}$ (C and D); $100 \mu \mathrm{m}(\mathbf{E}-\mathbf{J})$. 
significantly between patients with COVID-19 and controls, with the notable exception of one patient with COVID-19 who showed elevated levels of pSTAT3 expression on $17.5 \%$ of ECs (Figure 2H). This patient had suffered a cardiac arrest one day before death. Consistent with a paucity of evidence for endothelial cell responses to cytokines, there was no statistically significant increase in the expression of ICAM-1 (Figure 2I), VCAM-1 (Figure 2J), or E-selectin (Supplemental Figure S2) in patients compared to controls. The one patient with COVID-19 that showed increased VCAM-1 expression was the same patient described above that suffered a recent cardiac arrest. Supplemental Table S2 summarizes several of these histological findings.

\section{Activated Intravascular Neutrophils Feature \\ Prominently in Thrombi in Hearts of COVID-19 Decedents}

Thrombosis can also occur due to changes in the composition or activation of various components in the blood.
In contrast to the limited findings of endothelial alterations, the composition of thrombi revealed frequent presence of platelets associated with neutrophils (Figure 3, A and B) and many of these neutrophils stained positive for Citrullinated Histone 3 (CitH3), an early step in neutrophil extracellular trap (NET) formation. Eventually, these neutrophils will undergo NETosis, the expulsion of NETs or structures composed of chromatin, histones, and other internal neutrophil molecules that can bind pathogens or serve as sites of thrombosis. Evidence of NET formation was found in neutrophils at sties of thrombi in 4 of the 6 patients with COVID-19 with thrombi. Some images suggest NETs that appear to be directly associated with platelets (Figure 3C). Neutrophil-rich macrothrombi composed of $30 \%$ or more neutrophils were also common in COVID-19 but not control specimens (Figure 3, D and E). CitH3+ neutrophil-only aggregates also localized in vessels (Figure 3F). Many of these neutrophils appeared to have elevated expression of p65 (RelA), the significance of which is uncertain, but, like NET formation, may reflect an activated state (Figure 3G).

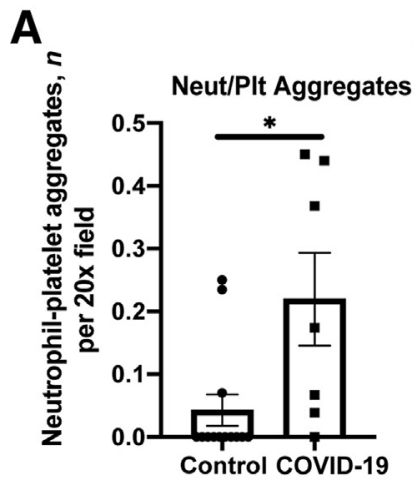

B

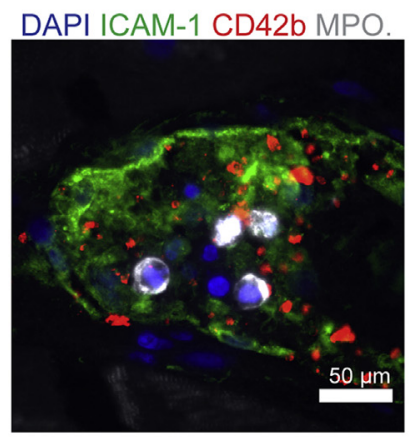

C

D

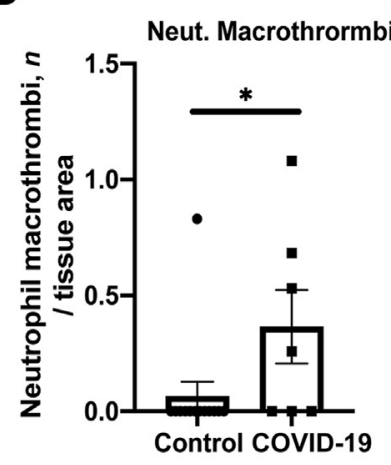

E

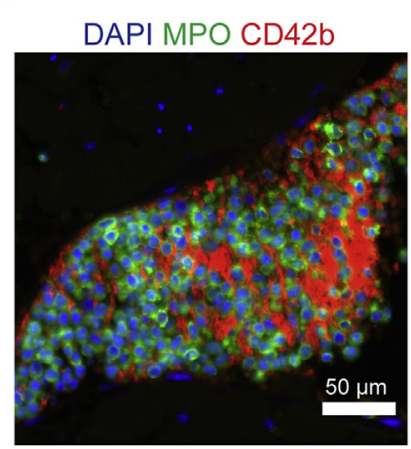

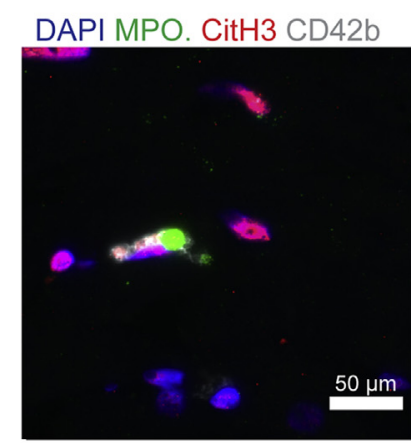

$\mathbf{F}$

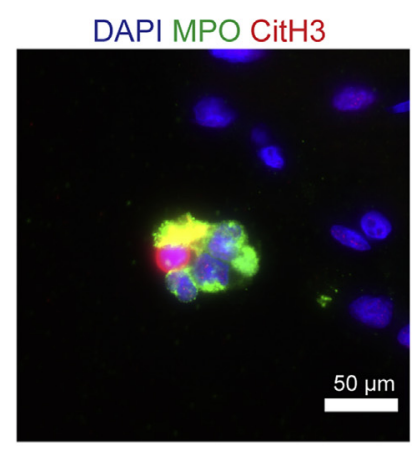

G

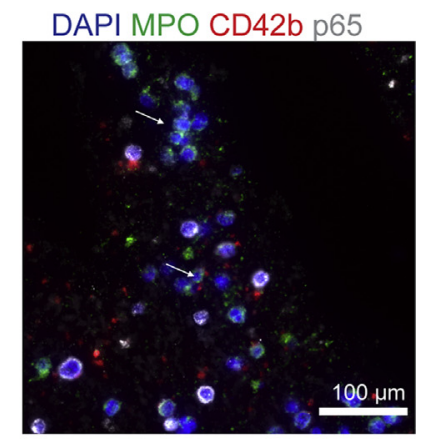

Figure 3 Neutrophils contribute to thrombosis in patients. A: The number of neutrophil-platelet aggregates per $20 \times$ field was quantified in patients and controls. B and C: Patient tissue images of neutrophil-platelet aggregates and a neutrophil during NETosis, capturing platelets. D: Neutrophil rich macrothrombi composed of more than $30 \%$ neutrophils were counted in entire tissue at $10 \times$. Values were normalized by tissue area. $\mathbf{E}$ and $\mathbf{F}$ : Images showing neutrophil macrothrombi and neutrophil aggregates that are $\mathrm{CitH} 3+$ in circulation in COVID-19 heart tissue. G: Image shows neutrophils with increased p65 expression (arrows) in COVID-19 tissue. Myeloperoxidase (MPO) was used to identify neutrophils and Citrullinated histone H3 (CitH3) to identify NET formation. Data represent means \pm SEM. ${ }^{*} P<0.05$. Scale bars: $50 \mu \mathrm{m}(\mathbf{B}, \mathbf{C}, \mathbf{E}$, and $\mathbf{F}) ; 100 \mu \mathrm{m}(\mathbf{G})$. 


\section{Discussion}

This study reports findings that agree with and extend the results of prior autopsy series of hearts from patients dying of COVID-19. It found thrombosis of micro and macro coronary vessels with little evidence of overt cardiac injury and an absence of direct infection, myocarditis, or antibody and complement binding, as seen on prior studies. ${ }^{12,14}$ It is not clear whether extensive thrombosis in the absence of overt myocyte injury compromises cardiac function, but low levels of circulating cardiac troponin concentrations correlate with morbidity and mortality in severe COVID-19 infections, indicative of low level and perhaps diffuse myocyte injury. To understand the likely causes of cardiac thrombosis, an extensive multiparameter IF analysis of COVID-19 autopsy heart tissue was performed using advanced morphologic methodology to discern the most likely causes of the COVID-19 coronary thrombotic diathesis. Despite the limited sample size and patient heterogeneity that made drawing conclusions from individual patients difficult, there was no consistent evidence that any of the markers for EC activation tested, including ICAM-1, VCAM-1 and p65 correlated with thrombosis, and only rare and isolated evidence of vessel injury or activation was seen. These data instead favor a hypothesis that the thrombotic diathesis results primarily from hypercoagulability of the blood caused by activated neutrophils.

During COVID-19 infection, platelets and neutrophils exhibit highly activated states with an increase in P-selectin surface expression on the former and Factor V, G-CSF, and IL-8 expression on the latter. ${ }^{24-26}$ Reports have also documented increased numbers of circulating neutrophil platelet aggregates ${ }^{27}$ and $\mathrm{CitH} 3+$ neutrophils in the blood and at sites of thrombi in the lung. ${ }^{28}$ Additionally, Blasco et $\mathrm{al}^{29}$ recently reported a case series on patients with COVID-19 who died of MI showing NETs within thrombi of the heart. The current findings agree with and extend these reports and suggest that neutrophils play a very prominent role in thrombosis of the heart in these patients with COVID-19.

Neutrophils may be activated to release NETs by recognition or infection of virus or bacteria, activation by cytokines, or interactions with platelets, complement and/ or antibodies. ${ }^{30}$ The current data in the heart favor a role of cytokines and platelets in promoting NETs with the finding of $\mathrm{CitH} 3+$ neutrophils in thrombi bound to platelets in the absence of virus, antibody, or complement. Minimal endothelial activation in the heart may be preventing neutrophils from entering the heart parenchyma unlike lungs of the same patient. Interestingly, the study also found neutrophil aggregates, which may serve as an additional thrombotic stimulus for platelet aggregation leading to larger thrombi.
Heparin therapy commonly administered to patients with COVID-19 to block coagulation may also prove to be beneficial in reducing NET-dependent thrombus formation in patients. This negatively-charged polymer can interact with positively-charged histones released by NETs, rendering them unable to activate platelets and potentiate thrombosis. ${ }^{31}$ Furthermore, heparin can activate DNAse $\mathrm{I}$ and bind P-selectin and ICAM-1 to reduce the interaction and binding of platelets and neutrophils to each other and to endothelial cells. $^{30,32}$

This study has several limitations. First, postmortem tissue samples provide only insights toward the end of the disease course and a final snapshot of possible mechanisms. Earlier events may have a different pattern, but cardiac tissue is not generally accessible for analysis before death. Second, the nature of multidimensional cyclic IF restricts the number of slides that can be examined, providing only limited sampling that may miss other areas with pathologic findings and is restricted to a small number of specimens. Nevertheless, we believe we are the first to apply multiparameter analyses, revealing the absence of vessel wall changes at the actual sites of thrombosis. The current data thus challenge the view that alterations in the vessel wall are the primary cause of COVID-19 cardiac thrombosis, a finding with implications for prophylaxis. Analysis of additional samples will be required to validate this conclusion. We also recognize that thrombosis in hearts, which do not appear to be sites of viral infection, may be different from the processes occurring in other sites, such as lung or the gut, in which virus and abundant inflammation is present.

In conclusion, the current multiparameter analysis of cardiac vessel thrombosis points to activation of circulating neutrophils as the most likely causal event. Alterations in the vessel wall, although seen in some instances, are relatively rare. In light of these findings, reducing neutrophil responses could be an important target for therapeutic intervention.

\section{Acknowledgment}

We thank Gregory Tietjen for use of microscope.

\section{Supplemental Data}

Supplemental material for this article can be found at http://doi.org/10.1016/j.ajpath.2021.09.004.

\section{References}

1. Huang L, Zhao P, Tang D, Zhu T, Han R, Zhan C, Liu W, Zeng H, Tao Q, Xia L: Cardiac involvement in patients recovered from COVID-2019 identified using magnetic resonance imaging. JACC Cardiovasc Imaging 2020, 13:2330-2339 
2. Shi S, Qin M, Shen B, Cai Y, Liu T, Yang F, Gong W, Liu X, Liang J, Zhao Q, Huang H, Yang B, Huang C: Association of cardiac injury with mortality in hospitalized patients with COVID-19 in Wuhan, China. JAMA Cardiol 2020, 5:802-810

3. Cummings MJ, Baldwin MR, Abrams D, Jacobson SD, Meyer BJ, Balough EM, Aaron JG, Claassen J, Rabbani LE, Hastie J, Hochman BR, Salazar-Schicchi J, Yip NH, Brodie D, O'Donnell MR: Epidemiology, clinical course, and outcomes of critically ill adults with COVID-19 in New York City: a prospective cohort study. Lancet 2020, 395:1763-1770

4. Santoso A, Pranata R, Wibowo A, Al-Farabi MJ, Huang I, Antariksa B: Cardiac injury is associated with mortality and critically ill pneumonia in COVID-19: a meta-analysis. Am J Emerg Med 2021, 44:352-357

5. Williamson EJ, Walker AJ, Bhaskaran K, Bacon S, Bates C, Morton CE, Curtis HJ, Mehrkar A, Evans D, Inglesby $\mathrm{P}$, Cockburn J, McDonald HI, MacKenna B, Tomlinson L, Douglas IJ, Rentsch CT, Mathur R, Wong AYS, Grieve R, Harrison D, Forbes H, Schultze A, Croker R, Parry J, Hester F, Harper S, Perera R, Evans SJW, Smeeth L, Goldacre B: Factors associated with COVID-19-related death using OpenSAFELY. Nature 2020, 584:430-436

6. Knight Daniel S, Kotecha T, Razvi Y, Chacko L, Brown James T, Jeetley Paramjit S, Goldring J, Jacobs M, Lamb Lucy E, Negus R, Wolff A, Moon James C, Xue H, Kellman P, Patel N, Fontana M: COVID-19. Circulation 2020, 142:1120-1122

7. Puntmann VO, Carerj ML, Wieters I, Fahim M, Arendt C, Hoffmann J, Shchendrygina A, Escher F, Vasa-Nicotera M, Zeiher AM, Vehreschild M, Nagel E: Outcomes of cardiovascular magnetic resonance imaging in patients recently recovered from coronavirus disease 2019 (COVID-19). JAMA Cardiol 2020, 5: $1265-1273$

8. Liaqat A, Ali-Khan RS, Asad M, Rafique Z: Evaluation of myocardial injury patterns and ST changes among critical and non-critical patients with coronavirus-19 disease. Sci Rep 2021, 11: 4828

9. Giustino G, Croft LB, Stefanini GG, Bragato R, Silbiger JJ, Vicenzi M, et al: Characterization of myocardial injury in patients with COVID19. J Am Coll Cardiol 2020, 76:2043-2055

10. Efros O, Barda N, Meisel E, Leibowitz A, Fardman A, Rahav G, Klempfner R, Grossman E: Myocardial injury in hospitalized patients with COVID-19 infection-risk factors and outcomes. PLoS One 2021, 16:e247800

11. Babapoor-Farrokhran S, Gill D, Walker J, Rasekhi RT, Bozorgnia B, Amanullah A: Myocardial injury and COVID-19: possible mechanisms. Life Sci 2020, 253:117723

12. Roshdy A, Zaher S, Fayed H, Coghlan JG: COVID-19 and the heart: a systematic review of cardiac autopsies. Front Cardiovasc Med 2021, 7 : 626975

13. Halushka MK, Vander Heide RS: Myocarditis is rare in COVID-19 autopsies: cardiovascular findings across 277 postmortem examinations. Cardiovasc Pathol 2021, 50:107300

14. Pellegrini D, Kawakami R, Guagliumi G, Sakamoto A, Kawai K, Gianatti A, Nasr A, Kutys R, Guo L, Cornelissen A, Faggi L, Mori M, Sato Y, Pescetelli I, Brivio M, Romero M, Virmani R, Finn AV: Microthrombi as a major cause of cardiac injury in COVID-19: a pathologic study. Circulation 2021, 143: $1031-1042$

15. Bois MC, Boire NA, Layman AJ, Aubry M-C, Alexander MP, Roden AC, Hagen CE, Quinton RA, Larsen C, Erben Y, Majumdar R, Jenkins SM, Kipp BR, Lin PT, Maleszewski JJ: COVID-19-associated nonocclusive fibrin microthrombi in the heart. Circulation 2021, 143: 230-243

16. Rapkiewicz AV, Mai X, Carsons SE, Pittaluga S, Kleiner DE, Berger JS, Thomas S, Adler NM, Charytan DM, Gasmi B, Hochman JS, Reynolds HR: Megakaryocytes and platelet-fibrin thrombi characterize multi-organ thrombosis at autopsy in COVID19: a case series. EClinicalMedicine 2020, 24:100434

17. Bonaventura A, Vecchié A, Dagna L, Martinod K, Dixon DL, Van Tassell BW, Dentali F, Montecucco F, Massberg S, Levi M, Abbate A: Endothelial dysfunction and immunothrombosis as key pathogenic mechanisms in COVID-19. Nat Rev Immunol 2021, 21:319-329

18. Du Z, Lin J-R, Rashid R, Maliga Z, Wang S, Aster JC, Izar B, Sorger PK, Santagata S: Qualifying antibodies for image-based immune profiling and multiplexed tissue imaging. Nat Protoc 2019, 14: $2900-2930$

19. Schindelin J, Arganda-Carreras I, Frise E, Kaynig V, Longair M, Pietzsch T, Preibisch S, Rueden C, Saalfeld S, Schmid B, Tinevez J-Y, White DJ, Hartenstein V, Eliceiri K, Tomancak P, Cardona A: Fiji: an open-source platform for biological-image analysis. Nat Methods 2012, 9:676-682

20. Koupenova M, Kehrel BE, Corkrey HA, Freedman JE: Thrombosis and platelets: an update. Eur Heart J 2017, 38:785-791

21. Bombeli T, Karsan A, Tait JF, Harlan JM: Apoptotic vascular endothelial cells become procoagulant. Blood 1997, 89:2429-2442

22. Bevilacqua MP, Pober JS, Wheeler ME, Cotran RS, Gimbrone MA Jr: Interleukin-1 activation of vascular endothelium. Effects on procoagulant activity and leukocyte adhesion. Am J Pathol 1985, 121: 394-403

23. Wagner DD, Bonfanti R: von Willebrand factor and the endothelium. Mayo Clin Proc 1991, 66:621-627

24. Wang J, Kotagiri P, Lyons PA, Mescia F, Bergamaschi L, Turner L, Al-Lamki RS, Morgan MD, Calero-Nieto FJ, Bach K, Mende N, Wilson NK, Watts ER, Chinnery PF, Kingston N, Papadia S, Stirrups K, Walker N, Gupta RK, Toshner M, Weekes MP, Nathan JA, Walmsley SR, Ouwehand WH, Kasanicki M, Göttgens B, Marioni JC, Smith KGC, Pober JS, Bradley JR: Factor V is an immune inhibitor that is expressed at increased levels in leukocytes of patients with severe Covid-19. medRxiv 2021, [Preprint] doi: 10.1101/2021.01.14. 21249801

25. Comer SP, Cullivan S, Szklanna PB, Weiss L, Cullen S, Kelliher S, Smolenski A, Murphy C, Altaie H, Curran J, O'Reilly K, Cotter AG, Marsh B, Gaine S, Mallon P, McCullagh B, Moran N, Ní Áinle F, Kevane B, Maguire PB: On behalf of the CSi: COVID-19 induces a hyperactive phenotype in circulating platelets. PLoS Biol 2021, 19: e3001109

26. Meizlish ML, Pine AB, Bishai JD, Goshua G, Nadelmann ER, Simonov M, Chang CH, Zhang H, Shallow M, Bahel P, Owusu K, Yamamoto Y, Arora T, Atri DS, Patel A, Gbyli R, Kwan J, Won CH, Dela Cruz C, Price C, Koff J, King BA, Rinder HM, Wilson FP, Hwa J, Halene S, Damsky W, van Dijk D, Lee AI, Chun HJ: A neutrophil activation signature predicts critical illness and mortality in COVID-19. Blood Adv 2021, 5: $1164-1177$

27. Manne BK, Denorme F, Middleton EA, Portier I, Rowley JW, Stubben C, Petrey AC, Tolley ND, Guo L, Cody M, Weyrich AS, Yost CC, Rondina MT, Campbell RA: Platelet gene expression and function in patients with COVID-19. Blood 2020, 136: $1317-1329$

28. Middleton EA, He X-Y, Denorme F, Campbell RA, Ng D, Salvatore SP, Mostyka M, Baxter-Stoltzfus A, Borczuk AC, Loda M, Cody MJ, Manne BK, Portier I, Harris ES, Petrey AC, Beswick EJ, Caulin AF, Iovino A, Abegglen LM, Weyrich AS, Rondina MT, Egeblad M, Schiffman JD, Yost CC: Neutrophil extracellular traps contribute to immunothrombosis in COVID-19 acute respiratory distress syndrome. Blood 2020, 136:1169-1179

29. Blasco A, Coronado M-J, Hernández-Terciado F, Martín P, Royuela A, Ramil E, García D, Goicolea J, Del Trigo M, Ortega J, Escudier JM, Silva L, Bellas C: Assessment of neutrophil extracellular traps in coronary thrombus of a case series of patients with COVID-19 and myocardial infarction. JAMA Cardiol 2021, 6: 469-474 
30. Ackermann M, Anders H-J, Bilyy R, Bowlin GL, Daniel C, De Lorenzo R, et al: Patients with COVID-19: in the dark-NETs of neutrophils. Cell Death Differ 2021:1-15

31. Bautista-Becerril B, Campi-Caballero R, Sevilla-Fuentes S, HernándezRegino LM, Hanono A, Flores-Bustamante A, González-Flores J, GarcíaÁvila CA, Aquino-Gálvez A, Castillejos-López M, Juárez-Cisneros A,
Camarena A: Immunothrombosis in COVID-19: implications of neutrophil extracellular traps. Biomolecules 2021, 11:694

32. Li Y, Wan D, Luo X, Song T, Wang Y, Yu Q, Jiang L, Liao R, Zhao W, Su B: Circulating histones in sepsis: potential outcome predictors and therapeutic targets. Front Immunol 2021, 12: 650184 